\title{
Experimental and Theoretical Mechanistic Investigation of the Iridium-Catalyzed Dehydrogenative Decarbonylation of Primary Alcohols
}

\author{
Olsen, Esben Paul Krogh; Singh, Thishana; Harris, Pernille; Andersson, Pher G.; Madsen, Robert
}

Published in:

Journal of the American Chemical Society

Link to article, DOI:

$10.1021 / j a 5106943$

Publication date:

2015

Document Version

Peer reviewed version

Link back to DTU Orbit

Citation (APA):

Olsen, E. P. K., Singh, T., Harris, P., Andersson, P. G., \& Madsen, R. (2015). Experimental and Theoretical Mechanistic Investigation of the Iridium-Catalyzed Dehydrogenative Decarbonylation of Primary Alcohols. Journal of the American Chemical Society, 137(2), 834-842. https://doi.org/10.1021/ja5106943

\section{General rights}

Copyright and moral rights for the publications made accessible in the public portal are retained by the authors and/or other copyright owners and it is a condition of accessing publications that users recognise and abide by the legal requirements associated with these rights.

- Users may download and print one copy of any publication from the public portal for the purpose of private study or research.

- You may not further distribute the material or use it for any profit-making activity or commercial gain

- You may freely distribute the URL identifying the publication in the public portal 


\title{
Experimental and Theoretical Mechanistic Investigation of the Iridi- um-Catalyzed Dehydrogenative Decarbonylation of Primary Alco- hols
}

\author{
Esben P. K. Olsen, ${ }^{\dagger}$ Thishana Singh, ${ }^{\ddagger}$ Pernille Harris, ${ }^{\dagger}$ Pher G. Andersson, ${ }^{* \ddagger}$ Robert Madsen ${ }^{\star \dagger}$ \\ ${ }^{\dagger}$ Department of Chemistry, Technical University of Denmark, 280o Kgs. Lyngby, Denmark \\ ${ }^{\ddagger}$ Department of Organic Chemistry, Stockholm University, 10691 Stockholm, Sweden
}

\begin{abstract}
The mechanism for the iridium-BINAP catalyzed dehydrogenative decarbonylation of primary alcohols with the liberation of molecular hydrogen and carbon monoxide was studied experimentally and computationally. The reaction takes place by tandem catalysis through two catalytic cycles involving dehydrogenation of the alcohol and decarbonylation of the resulting aldehyde. The square planar complex $\operatorname{IrCl}(\mathrm{CO})$ (rac-BINAP) was isolated from the reaction between $[\operatorname{Ir}(\operatorname{cod}) \mathrm{Cl}]_{2}$, rac-BINAP and benzyl alcohol. The complex was catalytically active and applied in the study of the individual steps in the catalytic cycles. One carbon monoxide ligand was shown to remain coordinated to iridium throughout the reaction and release of carbon monoxide was suggested to occur from a dicarbonyl complex. $\mathrm{IrH}_{2} \mathrm{Cl}(\mathrm{CO})$ (rac-BINAP) was also synthesized and detected in the dehydrogenation of benzyl alcohol. In the same experiment, $\operatorname{IrHCl}_{2}(\mathrm{CO})(\mathrm{rac}$-BINAP) was detected from the release of $\mathrm{HCl}$ in the dehydrogenation and subsequent reaction with $\operatorname{IrCl}(\mathrm{CO})$ (rac-BINAP). This indicated a substitution of chloride with the alcohol to form a square planar iridium alkoxo complex that could undergo a $\beta$-hydride elimination. A KIE of 1.0 was determined for the decarbonylation and 1.42 for the overall reaction. Electron rich benzyl alcohols were converted faster than electron poor alcohols, but no electronic effect was found when comparing aldehydes of different electronic character. The lack of electronic and kinetic isotope effects implies a rate determining phosphine dissociation for the decarbonylation of aldehydes.
\end{abstract}

\section{Introduction}

The acceptorless dehydrogenation of an alcohol into the corresponding carbonyl compound and molecular hydrogen is an important transformation that can be used both for hydrogen production ${ }^{1}$ and for in situ generation of carbonyl compounds in the presence of nucleophiles. ${ }^{2}$ The dehydrogenation is usually catalyzed by various ruthenium and iridium complexes and can be achieved in the absence of a stoichiometric additive such as a base., The mechanism has gained significant attention and has been the subject of both experimental ${ }^{3}$ and theoretical ${ }^{4}$ investigations. Depending on the nature of the ligands two pathways for hydrogen abstraction have been identified where the alcohol either coordinates to the metal (inner-sphere) or to a basic ligand (outer-sphere).,4

On the contrary, the decarbonylation of an aldehyde into the one-carbon shorter adduct and carbon monoxide has been less thoroughly studied. This transformation can be performed with rhodium, ${ }^{5}$ iridium $^{6}$ and palladium ${ }^{7}$ catalysts in the absence of a stoichiometric additive, but the mechanism has only been studied in detail with a rhodium catalyst. ${ }^{8}$ In this case, the transformation was shown to proceed by oxidative addition into the aldehyde $\mathrm{C}-\mathrm{H}$ bond followed by extrusion of carbon monoxide and reductive elimination. ${ }^{8}$
Recently, two of us presented an iridium catalyst that combines the dehydrogenation and the decarbonylation in one transformation. ${ }^{9}$ In this way, a primary alcohol is converted into the corresponding one-carbon shorter adduct with the release of both molecular hydrogen and carbon monoxide. The optimized conditions employed $\left[\operatorname{Ir}(\mathrm{coe}){ }_{2} \mathrm{Cl}\right]_{2}$, rac-BINAP and $\mathrm{LiCl}$ in refluxing mesitylene saturated with water (Scheme 1). ${ }^{9}$ The same conditions also facilitated the decarbonylation of aldehydes, which suggests that independent dehydrogenation and decarbonylation cycles are operating, and the reaction therefore is an example of a tandem catalytic transformation. ${ }^{10}$ Considerable attention has been devoted in recent years to the development of tandem catalytic processes where several reactions are performed consecutively in the same operation with one or more metal catalysts. ${ }^{10}$ However, thorough mechanistic studies of these transformations are still relatively rare in order to identify the catalytically active species and the interplay between the catalytic cycles."

$$
\begin{aligned}
& 2.5 \%\left[\operatorname{Ir}(\mathrm{Coe})_{2} \mathrm{Cl}\right]_{2} \\
& \mathrm{R} \widehat{\mathrm{OH}} \underset{\mathrm{mesitylene} / \mathrm{H}_{2} \mathrm{O}(150 \mathrm{ppm})}{\stackrel{5.0 \% \mathrm{rac}-\mathrm{BINAP}, 10 \% \mathrm{LiCl}}{\longrightarrow}} \underset{66-97 \%}{\mathrm{R}-\mathrm{H}}+\mathrm{H}_{2}+\mathrm{CO} \\
& 164^{\circ} \mathrm{C} \text {, inert atm. isolated yields }
\end{aligned}
$$

Scheme 1. The acceptorless dehydrogenative decarbonylation catalyzed by iridium and BINAP. 
Recently, we have applied the dehydrogenative decarbonylation as an ex situ generator of syngas in the hydroformylation of styrenes. ${ }^{12}$ Furthermore, the transformation of primary alcohols into their dehydroxymethylated counterparts has also been accomplished by a rhodium complex in a photocatalytic pathway ${ }^{13}$ and by a ligand free palladium catalyst. ${ }^{14}$ It is a transformation that has been suggested to play a future role in the defunctionalization of renewables in the replacement of fossil resources. ${ }^{15}$

Herein, we present a combined experimental and computational mechanistic investigation of the iridiumcatalyzed tandem reaction. The studies employ synthesis and detection of the major catalytic species, isotopelabeling experiments, kinetic studies and DFT calculations. The complex $\operatorname{IrCl}(\mathrm{CO})(\mathrm{BINAP})(\mathbf{1})$ has been identified as the key catalytically active intermediate and has been found to serve an interesting triple role in the transformation. It reacts with the alcohol in the dehydrogenation, with the aldehyde in the decarbonylation and with $\mathrm{HCl}$ as a mild and reversible acid scavenger.

\section{Results and Discussion}

To study the catalytic intermediates formed during the dehydrogenative decarbonylation, benzyl alcohol was chosen as the substrate since the product benzene could be easily removed by evaporation. Thus, a 1:2:3 ratio of $[\operatorname{Ir}(\mathrm{cod}) \mathrm{Cl}]_{2}$, rac-BINAP and benzyl alcohol were stirred in mesitylene at $110{ }^{\circ} \mathrm{C}$ for 60 min followed by removal of the solvent by distillation under reduced pressure along with dissociated cyclooctadiene and benzene. The remaining orange residue was analyzed by IR and ${ }^{31} \mathrm{P}$ NMR. IR spectroscopy revealed a strong peak at $1986 \mathrm{~cm}^{-1}$ corresponding to a carbonyl ligand and the very clean ${ }^{31} \mathrm{P}$ NMR spectrum showed only two doublets with a coupling constant of $29 \mathrm{~Hz}$. Applying $\alpha-\left[{ }^{13} \mathrm{C}\right]$-benzyl alcohol with $[\operatorname{Ir}(\operatorname{cod}) \mathrm{Cl}]_{2}$ and rac-BINAP resulted in a splitting of the two different doublets into two double doublets. The two new couplings constants were $123 \mathrm{~Hz}$ corresponding to a transcoupling and $11.2 \mathrm{~Hz}$ corresponding to a cis-coupling. The same coupling constants were found in a double duplet at $180.8 \mathrm{ppm}$, when recording a ${ }^{13} \mathrm{C}$ NMR spectrum of the $\left[{ }^{13} \mathrm{C}\right]$-enriched residue. These data comply with what is reported for complexes of the type $\operatorname{IrXCO}(\mathrm{P}-\mathrm{P})$, where $\mathrm{X}$ is a halide and (P-P) is a cis chelating phosphine. ${ }^{16}$

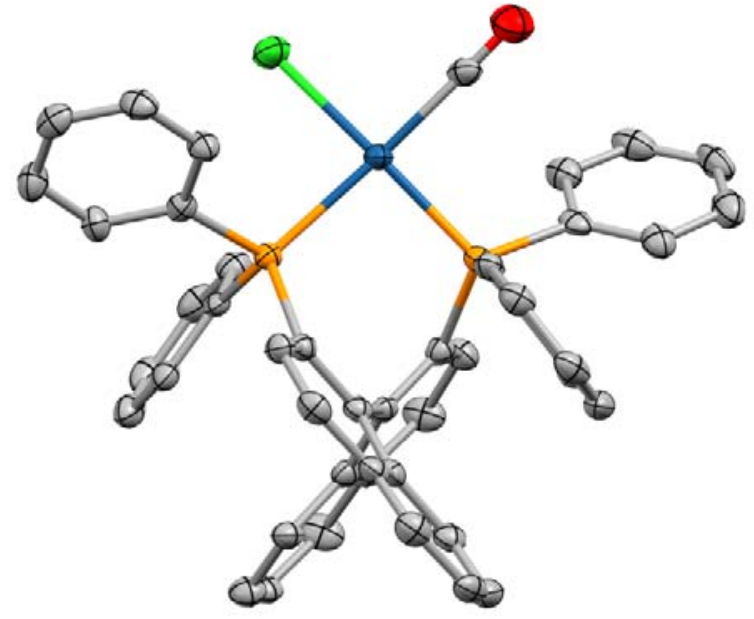

Figure 1. Crystal structure of $\operatorname{IrCl}(\mathrm{CO})(S)$-BINAP.

The structure was also confirmed by X-ray of a crystal obtained by slow addition of $\mathrm{Et}_{2} \mathrm{O}$ into a solution of $\operatorname{IrCl}(\mathrm{CO})(S)$-BINAP in $\mathrm{CH}_{2} \mathrm{Cl}_{2}$ (Figure 1). The strong coordination between carbon monoxide and iridium could not be disrupted by long term refluxing in mesitylene or long term storage on a vacuum line. This observation is consistent with the high bond dissociation energies reported for square planar iridium carbonyl complexes. ${ }^{17}$ The complex was catalytically active and kinetically very similar to the in situ formed catalyst. It could be stored under argon, but lost catalytic activity when exposed to air over a couple of days. The similarities in rate between the in situ formed and the pre-formed catalyst excluded any participating role of cyclooctadiene. This also made it possible to perform KIE measurements since cyclooctadiene, that had earlier caused scrambling of deuterium-labeled substrates, ${ }^{9}$ could now be excluded from the reaction mixture.

The KIE of the overall reaction was measured by comparing 2-hydroxymethylnaphthalene and $d_{3-2}$ hydroxymethylnaphthalene in a non-competitive experiment. The formation of naphthalene was followed by GCMS and an average of two experiments resulted in a KIE of $1.42 \pm 0.07$. Similarly, the decarbonylation of $2^{-}$ naphthaldehyde and 2- $\alpha$ - $d$-naphthaldehyde were compared in a non-competitive experiment and resulted in a KIE of $1.0 \pm 0.05$. The KIE of 1.42 was therefore assigned to the dehydrogenation cycle, and the value is considered too high for a normal secondary KIE. ${ }^{18}$

A Hammett study provides precious knowledge about the mechanism, but unfortunately due to the high reaction temperature and the low boiling point of the generated aryl compounds, a regular Hammett plot was not obtainable. Instead, three aryl alcohols affording high boiling products and with very different electronic properties were compared in competitive rate experiments. By measuring initial rates it was found that $3,4,5$ 
trimethoxybenzene was formed 1.5 times faster than naphthalene which was formed 2.5 fold faster than methyl benzoate as outlined in Figure 2.<smiles>COC(=O)c1ccc(CO)cc1</smiles>

Figure 2. Rate comparison of electronically different benzyl alcohols.

Interestingly, the decarbonylation of 3,4,5trimethoxybenzaldehyde and methyl 4-formylbenzoate were equally fast (supporting information), which also suggests that the electronic effect stems from the dehydrogenation cycle.

The reaction order in catalyst was determined to be $0.75 \pm 0.15$ for the dehydrogenative decarbonylation of $2-$ (2-naphthyl)ethanol. The aliphatic substrate was applied because aliphatic aldehydes do not accumulate in the tandem reaction and the reaction is thereby $\mathrm{o}^{\text {th }}$ order in the alcohol. The reaction order in catalyst for the decarbonylation of 2-naphthaldehyde was determined to be $0.85 \pm 0.08$. The non-integer reaction orders lower than 1.0 in both cases may indicate a higher degree of inactivation with increased catalyst concentration. However, the result can be used to preclude any theory of $2^{\text {nd }}$ order kinetics.

Experimental Study of Dehydrogenation. The liberated molecular hydrogen is expected to be reductively eliminated from an iridium dihydride species. The group of Eisenberg has investigated the oxidative addition of hydrogen to $\operatorname{IrX}(\mathrm{CO})(\mathrm{P}-\mathrm{P})$ complexes in order to form $\mathrm{IrH}_{2} \mathrm{X}(\mathrm{CO})(\mathrm{P}-\mathrm{P}){ }^{16,19}$ When $\operatorname{IrCl}(\mathrm{CO})$ (rac-BINAP) (1) was stirred in $\mathrm{CDCl}_{3}$ under a hydrogen atmosphere, $\mathrm{IrH}_{2} \mathrm{Cl}(\mathrm{CO})$ (rac-BINAP) isomers were rapidly formed. As discovered by Eisenberg, and illustrated in Figure 3, molecular hydrogen can add from above or below, or along the $\mathrm{P}-\mathrm{Ir}-\mathrm{CO}$ axis or the $\mathrm{P}-\mathrm{Ir}-\mathrm{Cl}$ axis, giving rise to four different isomers when a chiral ligand like BINAP is used. Labeling the starting complex with $\left[{ }^{13} \mathrm{C}\right] \mathrm{CO}$ makes it possible to distinguish between the diastereomers since complexes $\mathbf{2 A}$ and $\mathbf{2 B}$ have a trans coupling between $\mathrm{H}$ and $\left[{ }^{3} \mathrm{C}\right] \mathrm{CO}$ while complexes $3 \mathbf{A}$ and $\mathbf{3} \mathbf{B}$ only have cis couplings. A ${ }^{1} \mathrm{H}$ NMR spectrum recorded after $30 \mathrm{~min}$ of reaction time with hydrogen revealed that only isomers $\mathbf{2 A}$ and $\mathbf{2 B}$ were formed (Figure $4 \mathrm{~A}$ ). The effect is electronic and is caused by the ability of $\mathrm{CO}$ to stabilize the $\operatorname{Ir}\left(\mathrm{H}_{2}\right) \mathrm{Cl}(\mathrm{CO})($ rac-BINAP) trigonal bipyramidal transition state in the $\mathrm{H}_{2}$ oxidative addition. ${ }^{16}$ Interestingly, the ratio between the two diastereomers remained 3:1 over time, whereas Eisenberg who investigated the same reaction but with iodide as the counterion, observed a rapid scrambling of the isomers in deuterated benzene. ${ }^{16}$

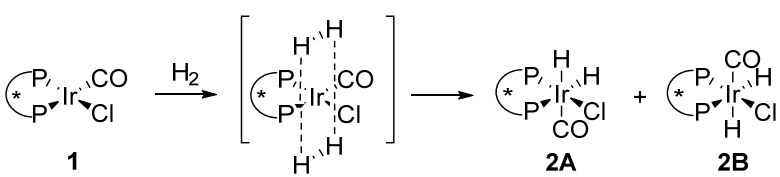

${ }^{*}{ }_{P}^{P}=$ BINAP

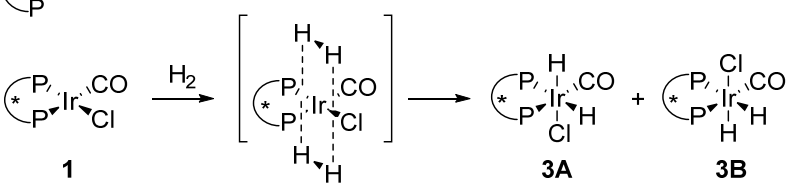

Figure 3. Oxidative addition of dihydrogen leading to four different isomers.

Reductive elimination of hydrogen from $\mathrm{IrH}_{2} \mathrm{Cl}(\mathrm{CO})$ (rac-BINAP) is essential to regenerate the catalytic starting material. To investigate the conditions necessary to accomplish this, the following procedure was employed: the mixture of $\mathbf{2 A}$ and $\mathbf{2 B}$, formed from oxidative addition of hydrogen in $\mathrm{CDCl}_{3}$, was divided into three portions followed by removal of $\mathrm{CDCl}_{3}$ by evaporation. The residues were taken up in benzene, toluene and mesitylene, respectively. The aromatic solvents were removed by distillation at atmospheric pressure and the residues were dissolved in $\mathrm{CDCl}_{3}$ and analyzed by ${ }^{1} \mathrm{H}$ NMR. As seen in the spectrum (Figure $4 \mathrm{~B}$ ), recorded after the removal of benzene, new peaks assigned to isomers ${ }_{3} \mathbf{A}$ and $\mathbf{3} \mathbf{B}$, appeared. Increasing the temperature, as was done when toluene was removed by distillation, resulted in complete isomerization (Figure $4 \mathrm{C}$ ). Interestingly, the conditions were not harsh enough for molecular hydrogen to be released, but when mesitylene was removed by distillation, the hydride signals vanished completely and a ${ }^{31} \mathrm{P}$ NMR spectrum confirmed the regeneration of complex 1.

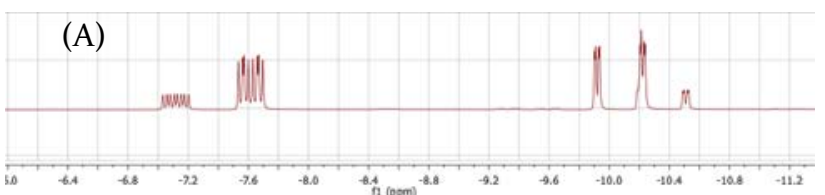

(B)

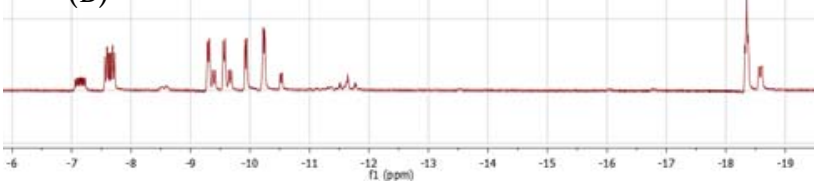

(C)

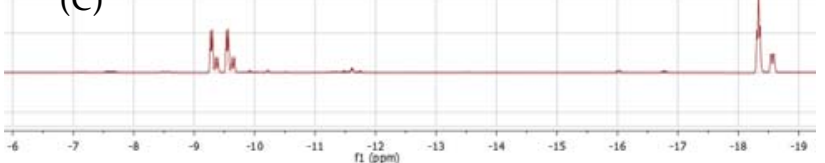

Figure 4. Hydride region in ${ }^{1} \mathrm{H}$ NMR spectra. (A) Spectrum recorded after 30 min where only hydrides from the kinetic isomers $\mathbf{2 A}$ and $\mathbf{2 B}$ are observed. (B) Spectrum recorded after removal of benzene, where an isomerization had started to occur. (C) Spectrum recorded after removal of toluene, 
where complete isomerization into the thermodynamic isomers $\mathbf{3} \mathbf{A}$ and $\mathbf{3} \mathbf{B}$ had occurred.

Since refluxing in toluene is not sufficient for the reductive elimination of hydrogen, we envisioned that isomers of the dihydride complexes could be detected along the catalytic pathway by reacting $\mathbf{1}$ with a primary alcohol. Thus, after refluxing 1 with benzyl alcohol for $4 \mathrm{~h}$, toluene was removed by distillation and the residue taken up in $\mathrm{CDCl}_{3}$ and analyzed by ${ }^{1} \mathrm{H}$ NMR. Only the hydride region is shown in Figure 5 (full spectrum included in the supporting information).

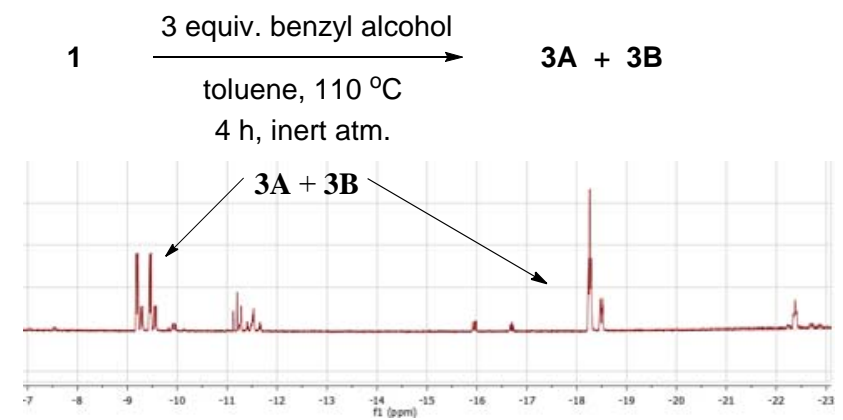

Figure 5. Hydride region recorded after removal of toluene from a reaction of $\mathbf{1}$ with benzyl alcohol.

The spectrum clearly shows formation of the dihydride complexes $\mathbf{3 A}$ and $\mathbf{3} \mathbf{B}$. Only a small amount of benzyl alcohol was converted at this temperature, which may indicate the formation of dihydride to be of high activation energy or the alcohol activation to be reversible. To determine a potential equilibrium, the dihydride complexes $\mathbf{2 A}$ and $\mathbf{2 B}$ were stirred with a stoichiometric amount of 2-naphthaldehyde. An aliquot was taken after 3 $h$ and analyzed by GC-MS, which revealed that $32 \%$ of the aldehyde had been converted to 2hydroxymethylnaphthalene. The detection of $3 \mathbf{A}+{ }_{3} \mathbf{B}$ isomers in the reaction of $\mathbf{1}$ with benzyl alcohol and the evidence for reversibility, strongly suggests the CO ligand to remain coordinated to iridium throughout the dehydrogenation cycle. With this in mind, several possible routes were envisioned as illustrated in Scheme 2.

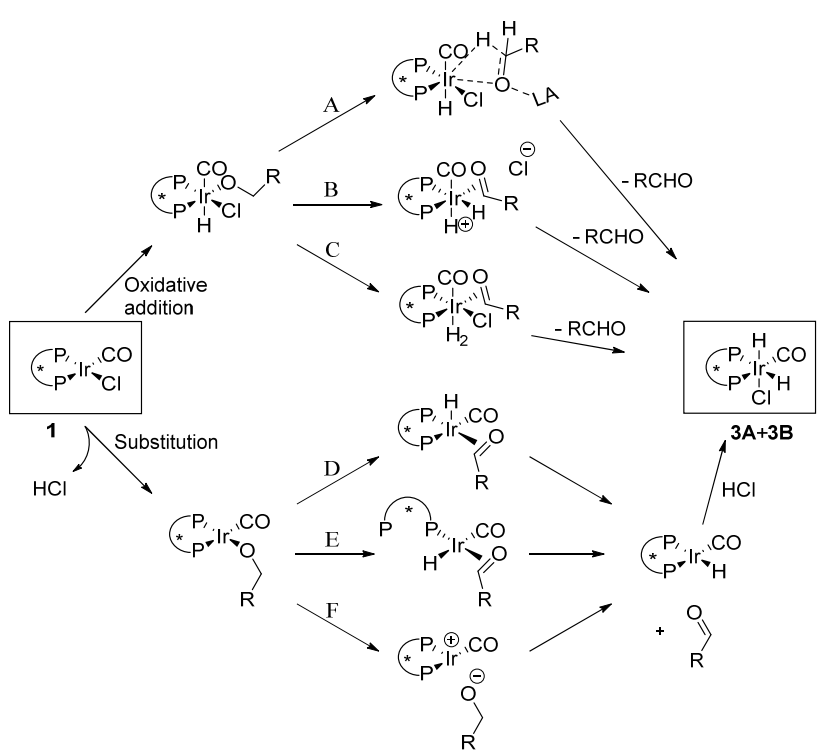

Scheme 2. Possible routes to formation of $3 \mathbf{A}$ and ${ }_{3} \mathbf{B}$. A) Pathway without a vacant site. B) Chloride dissociation followed by $\beta$-hydride elimination and ligand substitution. C) Hydride extracts the $\alpha$-proton forming a dihydrogen complex. D) Direct $\beta$-hydride elimination from the square planar iridium alkoxo complex. E) Phosphine dissociation prior to $\beta$-hydride elimination. F) Ionic pathway.

The pathways are separated into two major subgroups: oxidative addition of alcohol to iridium ${ }^{20}$ affording fully saturated complexes and substitution of the chloride ligand with the alcohol yielding square planar iridium alkoxo complexes by the release of $\mathrm{HCl}$. The oxidative addition products lack a vacant site for a $\beta$-hydride elimination. In pathway $A$, a vacant site is not necessary as a similar case was reported by Milstein. ${ }^{21}$ In pathway B, chloride dissociates to create the vacant site in an unsaturated cationic complex. In path $C$, molecular hydrogen is formed directly. A common feature in pathways D, E and $\mathrm{F}$ is the formation of the square planar iridium alkoxo complex which is closely related to the Vaska analog $\operatorname{Ir}(\mathrm{CO})\left(\mathrm{PPh}_{3}\right)_{2}(\mathrm{OR})$ investigated by Hartwig. ${ }^{22}$ In pathway $\mathrm{D}$, the $\beta$-hydride elimination takes place directly from the tetra-substituted square planar complex. In pathway $\mathrm{E}$, the phosphine dissociates prior to $\beta$-hydride elimination and pathway $\mathrm{F}$ represents an ionic route where the alkoxide could be stabilized by hydrogen bonding or a Lewis acid. Hartwig found that electron donating groups enhance the rate of $\beta$-hydride elimination from iridium alkoxo complexes and rationalized the observation with either greater stability of the resulting more electron rich aldehyde complex or lowering the barrier for migration of the hydrogen with partial hydridic character. ${ }^{22}$ Hence, the electronic effect, illustrated in Figure 2, does not only dictate positive charge buildup as a result of chloride dissociation, but can also be used to exclude pathway $\mathrm{F}$ from the speculations. In the substitution pathways, $\mathrm{HCl}$ is formed and liberated, but has to remain in solution to re-form the dihydride complex after $\beta$-hydride elimina- 
tion. In 1968 Vaska noticed that the oxidative addition of $\mathrm{HCl}$ to Vaska's complex $\operatorname{IrCl}(\mathrm{CO})\left(\mathrm{PPh}_{3}\right)_{2}$ is reversible, ${ }^{23}$ which persuaded us to investigate whether complex 1 would have similar chemical properties. In a $\mathrm{CDCl}_{3}$ solution of $\mathbf{1}, \mathrm{HCl}$ was formed in situ from ethanol and acetyl chloride. The crude mixture was analyzed by ${ }^{1} \mathrm{H},{ }^{13} \mathrm{C}$ and ${ }^{31} \mathrm{P}$ NMR. Complete conversion was readily obtained and the coupling pattern in the spectra indicated formation of the oxidative addition product $\operatorname{IrHCl}_{2}(\mathrm{CO})$ (rac-BINAP) (4). The structure was also confirmed by X-ray crystallography of a crystal obtained by slow addition of $\mathrm{Et}_{2} \mathrm{O}$ into a solution of 4 in $\mathrm{CH}_{2} \mathrm{Cl}_{2}$ (Figure 6).

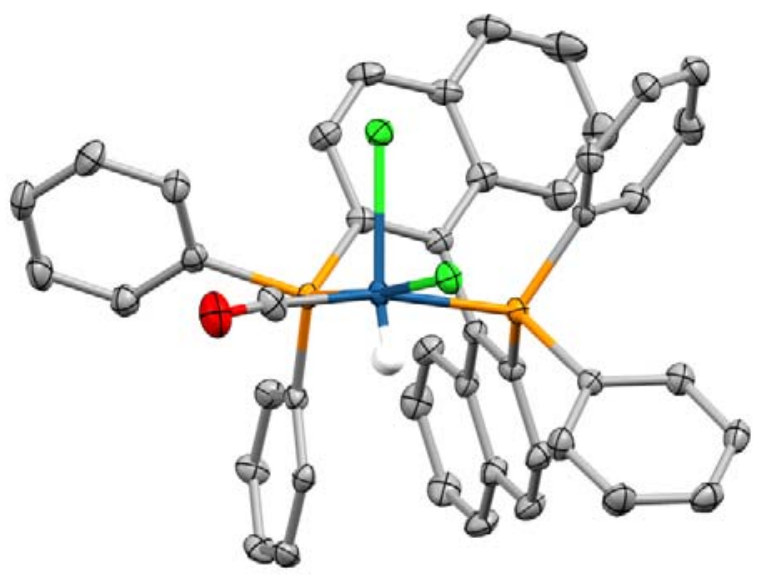

Figure 6. Crystal structure of $\operatorname{IrHCl}_{2}(\mathrm{CO})(R)$-BINAP.

A re-examination of the spectrum in Figure 5, which was recorded from the reaction between 1 and benzyl alcohol at $110{ }^{\circ} \mathrm{C}$, show the peaks from the two isomers of 4 at -16.8 and $-16.0 \mathrm{ppm}$, indicating $\mathrm{HCl}$ formation under these reaction conditions.

The iridium monohydride complexes depicted in pathway $\mathrm{D}$ and $\mathrm{E}$ were investigated by reacting $\mathbf{l}$ with sodium benzyl alkoxide at $110{ }^{\circ} \mathrm{C}$ for $3 \mathrm{~h}$. Benzaldehyde formation was observed without the concomitant formation of $3 \mathrm{~A}$ and $3 \mathbf{B}$. Instead an unknown iridium hydride complex was observed at $-11.2 \mathrm{ppm}$ in the ${ }^{1} \mathrm{H}$ NMR spectrum. The pattern showed a triplet with coupling constants of 39.2 $\mathrm{Hz}$, which lies in-between the coupling constants that had been observed for P-H cis- and trans-couplings in this study. Applying $\left[{ }^{13} \mathrm{C}\right]$-labelled $\mathbf{1}$ splits the triplet into a triple quintet indicating a complicated cluster formation (Scheme 3). The pattern from this cluster and a similar one at -11.6 ppm could also be found in the ${ }^{1} \mathrm{H}$ NMR spectrum in Figure 5. This pattern is also observed when forming $\mathbf{2} \mathbf{A}$ and $\mathbf{2 B}$ from $\mathbf{1}$ under a hydrogen atmosphere (Figure $4 \mathrm{~A}$ ). The clusters are not expected to be on the catalytic pathway, since their patterns do not disappear upon heating. Catalytically inactive iridium clusters have been reported in many cases. $^{24}$ Tetra-coordinated iridium monohydride carbonyl complexes appear to be rather unstable as the related complex $\operatorname{IrH}(\mathrm{CO})\left(\mathrm{PPh}_{3}\right)_{2}$ also seemed to aggregate in a study of $\beta$-hydride eliminations from $\operatorname{Ir}(n$-octyl $)(\mathrm{CO})\left(\mathrm{PPh}_{3}\right)_{2}{ }^{25}$

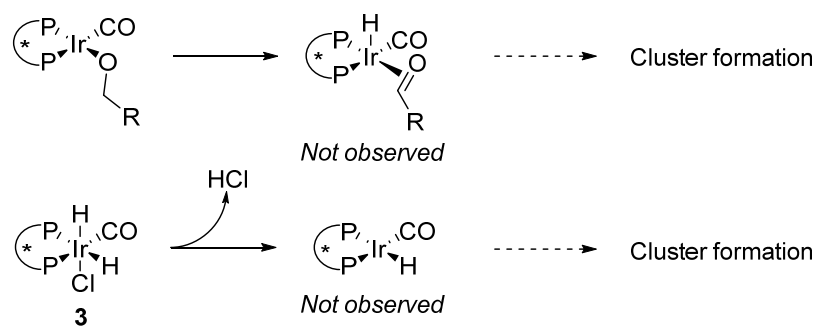

Scheme 3. Unstable monohydride species leading to cluster formation.

These observations favor route D since both 4 and the iridium cluster by-product from the decomposition of the square planar iridium alkoxo complex are detected in the reaction of 1 with benzyl alcohol (Figure 5). Complex 4 does catalyze the dehydrogenative decarbonylation, but it is not faster than 1, although it is easier to handle since it can be stored on the shelf, outside a glovebox, and without any sign of decomposition after several months.

In addition, a 3:1 mixture of $\mathbf{1}$ and $\mathbf{4}$ was stirred with benzyl alcohol at $110{ }^{\circ} \mathrm{C}$ to investigate changes in the hydride region. The hydride region resulting from this reaction is depicted in Figure 7 and by comparison with Figure 5 , it is clear that formation of the cluster at $-11.2 \mathrm{ppm}$ has been inhibited.

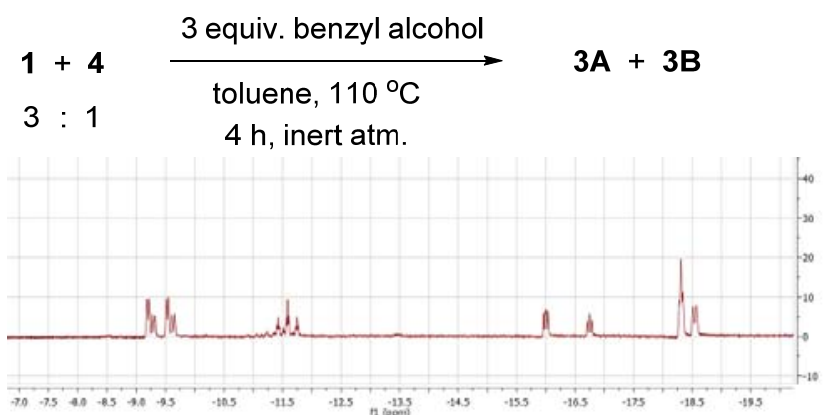

Figure 7. Hydride region recorded after removal of toluene from a reaction of $\mathbf{1}$ and $\mathbf{4}$ with benzyl alcohol.

Computational Study of Dehydrogenation. The dehydrogenation pathways in Scheme 2 were also evaluated by DFT calculations using the crystal structure of $\mathbf{1}$ as the starting point and benzyl alcohol as the substrate. From the calculations, a total energy $\Delta G_{\text {tot }}$ was calculated using the formula $\Delta G_{\text {tot }}=\Delta G-E_{\text {scf }}+E_{\text {solv }}$ where $\Delta G$ represents the Gibbs free energy, $E_{\text {scf }}$ is the gas phase energy and $E_{\text {solv }}$ the solution phase energy in mesitylene. This method, originally proposed by Wertz, ${ }^{26}$ has been applied in many theoretical investigations of transition metal catalytic cycles. $^{3 \mathrm{c}, 8}$

The two routes with the lowest activation energies were pathways $C$ and $D$. We did not succeed in calculating the energy profile for path $E$, because as soon as we forced one of the phosphines in BINAP to dissociate, it reassociated in the following optimization. Pathway $\mathrm{C}$ is 
initiated by an oxidative addition, which has a very high activation barrier of $50.3 \mathrm{kcal} / \mathrm{mol}$ (Figure 8 , cTs1). The depicted isomer of the oxidative addition product $(\mathrm{cr})$ is not the most stable isomer, but it has the lowest barrier of formation among the different isomers. The following hydride elimination forming molecular hydrogen directly has a barrier of $32.3 \mathrm{kcal} / \mathrm{mol}$ (cTS2). Notably, the formation of molecular hydrogen occurs simultaneously with an increase in the distance between the iridium center and oxygen giving rise to complex c2 where the aldehyde is no longer coordinated to iridium. The experimental observation of dihydride complexes $3^{\mathbf{A}}$ and ${ }_{3} \mathbf{B}$ can be explained by oxidative addition of molecular hydrogen to form $\mathbf{2 A}$ and $\mathbf{2 B}$ followed by an isomerization to ${ }_{3} \mathbf{A}$ and $\mathbf{3} \mathbf{B}$ which was proven possible experimentally. The elimination of molecular hydrogen has a low activation energy and since the overall dehydrogenation is endothermic it must be driven by the removal of hydrogen.

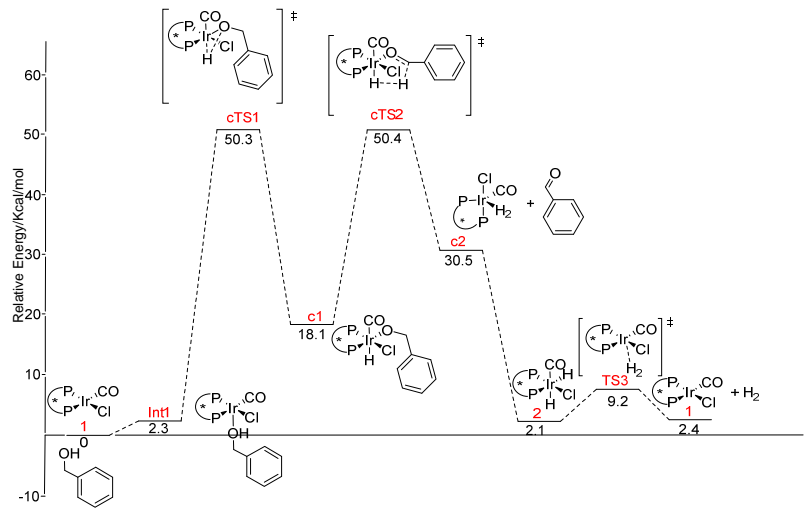

Figure 8. Energy profile for the dehydrogenation pathway $C$.

Pathway D is initiated by the substitution of chloride with benzyl alcohol (Scheme 4). The transition state that results in the formation of $\mathrm{HCl}$ has a free energy of 21.1 $\mathrm{kcal} / \mathrm{mol}$, and upon dissociation of $\mathrm{HCl}$ into solution, the energy of the alkoxo complex $\mathrm{d} 2$ is $28.9 \mathrm{kcal} / \mathrm{mol}$. With a base present the energy should be substantially lower.

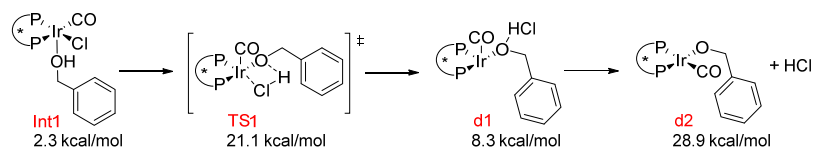

Scheme 4. Substitution of chloride with benzyl alcohol.

If the parent complex $\mathbf{1}$ acts as the base and absorbs $\mathrm{HCl}$ the energy is lowered by $10.7 \mathrm{kcal} / \mathrm{mol}$ (Figure 9). The $\beta$-hydride elimination is $29.8 \mathrm{kcal} / \mathrm{mol}$ higher in energy than $\mathrm{d} 2$ and the overall energetic span is slightly lower than in pathway $C$. In addition, the substitution with the alcohol is considerably more favorable than the oxidative addition in pathway $C$. As a result, the calculations also suggest pathway D to be the most likely route with complex 1 serving the additional role as acid scavenger (Figure 9). ${ }^{27}$

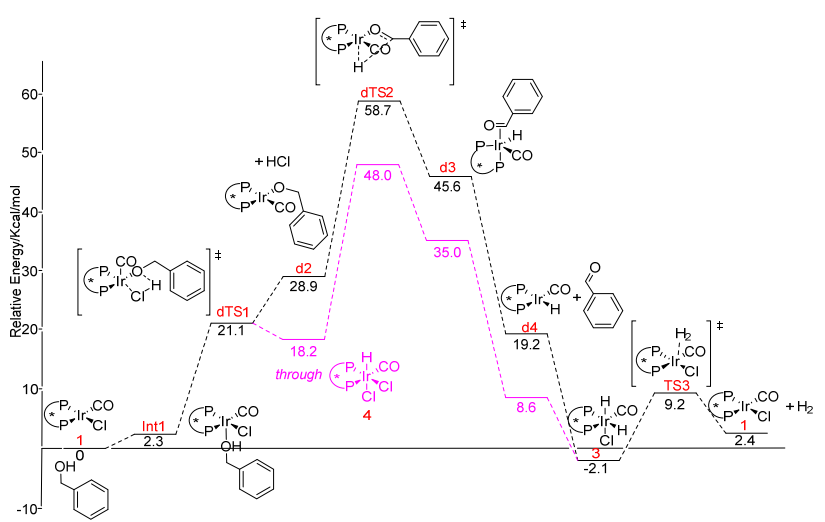

Figure 9. Energy profile for the dehydrogenation pathway D.

Experimental Study of Decarbonylation. Convinced that carbon monoxide is too tightly bound to 1 under the reaction conditions, it was thus expected that $\mathrm{CO}$ will be liberated from an iridium dicarbonyl species. Isolation of the dicarbonyl complex $\operatorname{IrCl}(\mathrm{CO})_{2}$ (rac-BINAP) (5) under the reaction conditions has not been accomplished, probably because $\mathrm{CO}$ addition is reversible. Instead, the Skrydstrup $\mathrm{CO}$ generating system ${ }^{28}$ was used to add one equivalent of $\mathrm{CO}$ to a $\mathrm{CDCl}_{3}$ solution of $\left[{ }^{13} \mathrm{C}\right]-\mathbf{1}$ in a twochamber setup. Mesitylene was added and then removed by distillation to completely release one of the carbon monoxide ligands. A ${ }^{31} \mathrm{P}$ NMR spectrum of the resulting residue was recorded and revealed a 1:1.3 ratio between 1 and $\left[{ }^{13} \mathrm{C}\right]-\mathbf{1}$ (Scheme 5 ). This observation is in compliance with the ability of Vaska's complex to coordinate an additional carbonyl ligand. ${ }^{29}$

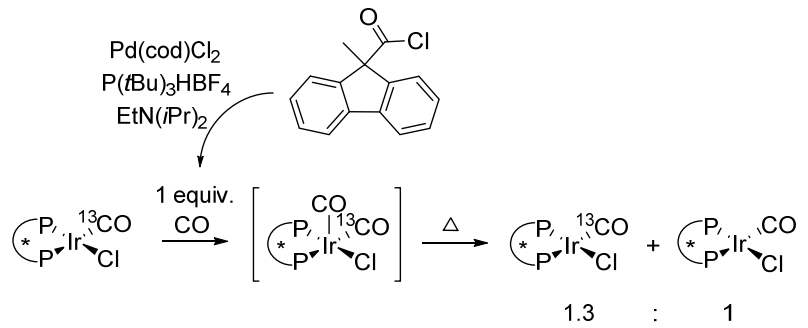

Scheme 5. CO scrambling with the Skrydstrup CO generator in a two-chamber setup.

Even though $\operatorname{IrCl}(\mathrm{CO})_{2}$ (rac-BINAP) is not sufficiently stable to be isolated, Eisenberg had synthesized $\left[\operatorname{Ir}(\mathrm{CO})_{2}(R)\right.$-BINAP] $\left[\mathrm{SbF}_{6}\right]$ and found that this complex was stable enough to be isolated by crystallization. ${ }^{16}$ With this is mind, complex 1 was mixed with benzaldehyde and stirred in benzene at $80^{\circ} \mathrm{C}$ for $3 \mathrm{~h}$. Benzene was removed by evaporation and a solution of $\mathrm{AgSbF}_{6}$ in $\mathrm{CH}_{2} \mathrm{Cl}_{2}$ was added to the remaining residue. After stirring for $1 \mathrm{~h}$ at room temperature the reaction mixture was filtered and dry $\mathrm{Et}_{2} \mathrm{O}$ was added to the filtrate. The resulting precipitate matched the spectroscopic data for $\left[\operatorname{Ir}(\mathrm{CO})_{2}(R)\right.$ BINAP] $\left[\mathrm{SbF}_{6}\right]{ }^{16}$

It is generally accepted that in transition metal mediated decarbonylations of aldehydes, the aldehyde oxidative- 
ly adds to the transition metal by activation of the $\mathrm{C}-\mathrm{H}$ bond. ${ }^{8,3^{\circ}}$ However, oxidative addition of an aldehyde to $\mathbf{1}$, will form a saturated iridium(III) complex with no vacant sites for migration. Since no kinetic isotope effect and no charge buildup were found, the steps in-between oxidative addition and $\mathrm{CO}$ dissociation are not immediately apparent. Five different pathways, illustrated in Scheme 6, have been evaluated. Radical pathways have been omitted, since a broad range of substrates including aryl halides are fully converted under the catalytic conditions. ${ }^{9}$ Pathway $G$ is inspired by the mechanism suggested for the rhodium-catalyzed decarbonylation ${ }^{8}$ where a substitution initiates a cationic pathway. In pathway $\mathrm{H}$, chloride dissociates to create a vacant site for the migratory extrusion. Pathway I and J are similar since the $\mathrm{R}$ group does not migrate to iridium, and both cases are triggered by an analogous example reported by Bergman..$^{31}$ In pathway $\mathrm{K}$, one of the phosphines in BINAP dissociates to create a vacant site for migration. In principle a similar pathway with $\mathrm{CO}$ dissociation could also be envisioned, but since the experimental studies show tight bonding of one CO ligand to iridium it was decided not to include this possibility in the evaluation.

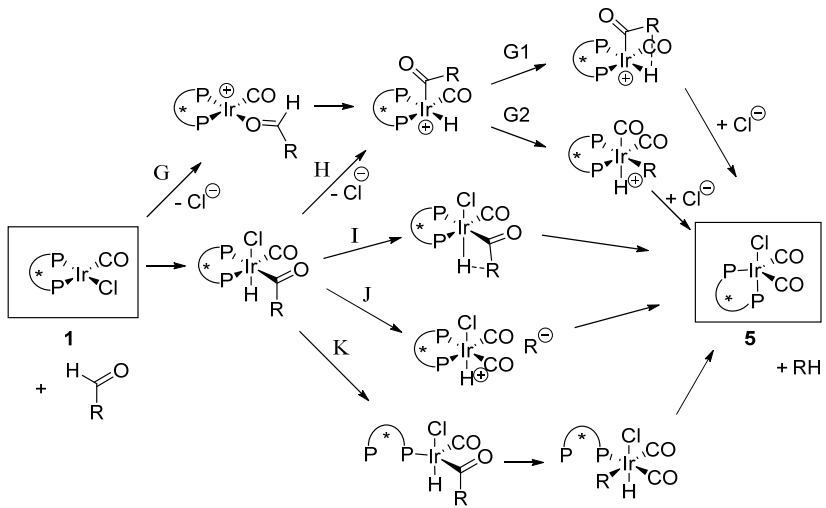

Scheme 6. Possible pathways for the decarbonylation of aldehydes. G) Substitution pathway. H) Oxidative addition followed by dissociation of chloride. I) A concerted migration pathway. J) R dissociates from the acyl complex. K) Phosphine dissociation pathway.

In the decarbonylation reported by Bergman, ${ }^{31}$ deuterium incorporation into the product was observed when using $\mathrm{CD}_{3} \mathrm{OD}$ as the solvent which strongly supports their proposed mechanism with dissociation of an anionic $\mathrm{R}$ group into solution. With this in mind, the deuterated aldehyde, $\alpha-d-3,4,5$-trimethoxybenzaldehyde was decarbonylated in the presence of two equivalent $\alpha, \alpha$ dimethylbenzyl alcohol, a tertiary alcohol not able to undergo dehydrogenation. Furthermore the same deuterated aldehyde was decarbonylated by $33 \mathrm{~mol} \%$ of 4 , which would dissociate $\mathrm{HCl}$ prior to the decarbonylation. The isolated products observed in both experiments had no proton incorporation which eliminates pathway J. Pathway I was investigated by DFT calculations since it was the only neutral pathway, besides the phosphine dissociation pathway, that could be directly compared to the energies which were obtained in the dehydrogenation cycle. It is difficult to compare ionic pathways to neutral pathways using computational methods, but the apolar reaction environment created by mesitylene should disfavor ionic pathways.

Computational Study of Decarbonylation. A similar methodology that was used for the dehydrogenation, was also applied for the decarbonylation: the crystal structure of $\mathbf{1}$ was used as the starting point and benzaldehyde was used as the substrate.

The oxidative addition of benzaldehyde to $\mathbf{1}$ leads to saturated iridium(III) species. All the possible isomers were optimized and the relative Gibbs free energies were compared (Figure 10). Even though the isomers with the acyl group in the apical position with respect to BINAP have the highest energies, the barriers for their formation were significantly lower than for the two other isomers. The lowest energy of $34.5 \mathrm{kcal} / \mathrm{mol}$ (Figure 11, iTS1) was found for the formation of the isomer with the acyl group coordinated trans to chloride.
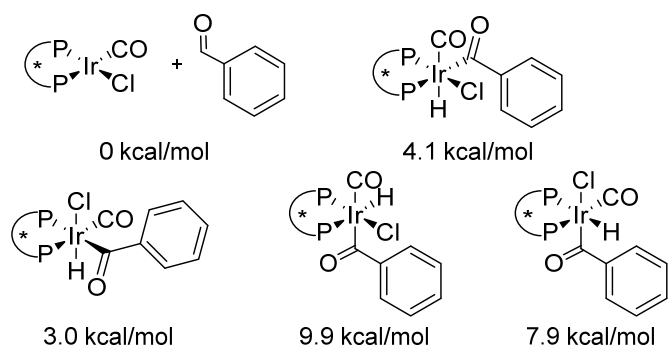

Figure 10. The four different geometrical isomers formed from oxidative addition of benzaldehyde.

The barrier for the reductive elimination through a four-membered transition state was very high for all the isomers. The lowest was found to be $\mathbf{5 2 . 2} \mathrm{kcal} / \mathrm{mol}$ (Figure 11, iTS2) and again this was observed for the isomer with the acyl group coordinated trans to chloride. We would, however, expect an energy profile with relative free energies closer to those in the dehydrogenation cycle and hence this makes pathway I unlikely. 


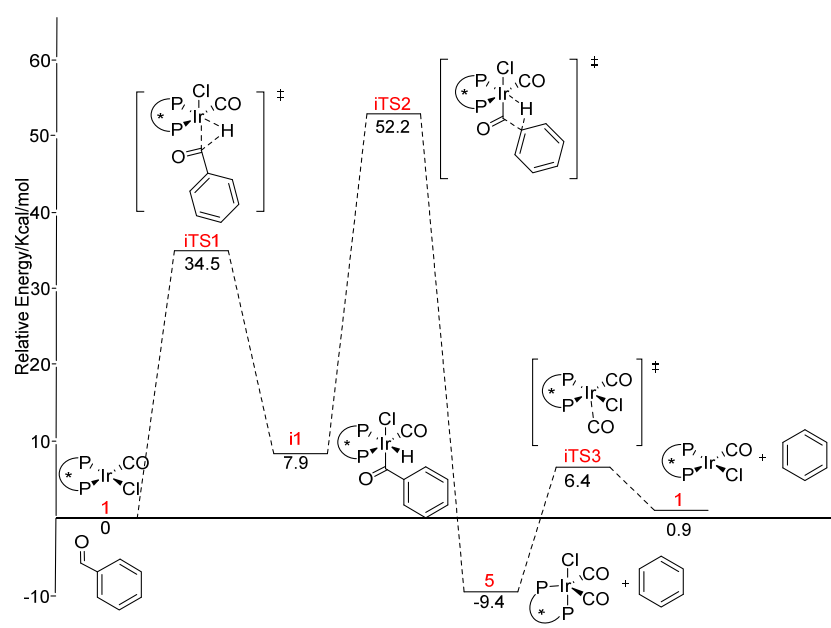

Figure 11. The lowest energy profile of the decarbonylation pathway I.

The lowest energy profile for the decarbonylation through pathway $\mathrm{K}$ was also calculated and is illustrated in Figure 12. Unfortunately, the transition state between the saturated oxidative addition product kı and the phosphine dissociated species $\mathbf{k} 2$ could not be located. The migratory extrusion of carbon monoxide takes place through transition state $\mathrm{kTS} 1$ with a relative Gibbs free energy of $41.6 \mathrm{kcal} / \mathrm{mol}$. The following reductive elimination of benzene from $\mathrm{k}_{3}$ occurs rather readily through transition state kTS2.

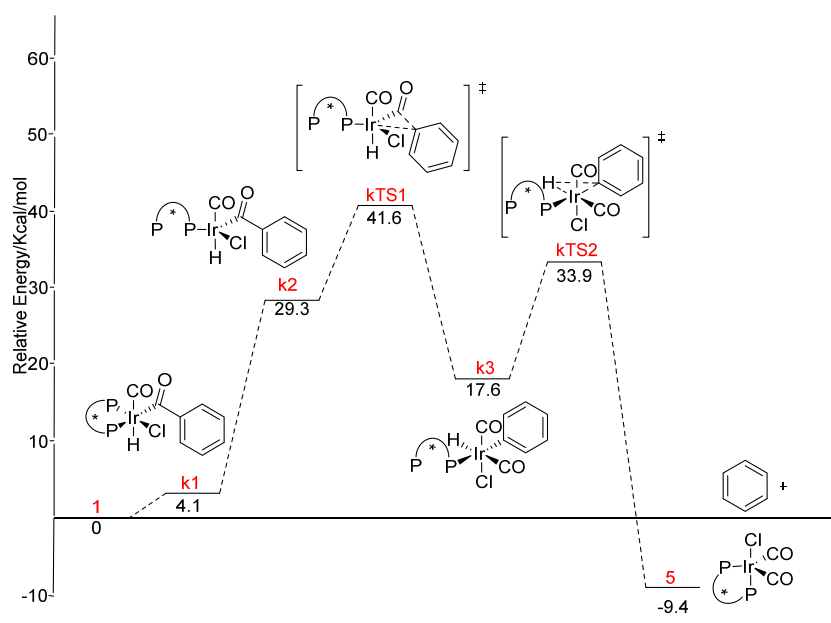

Figure 12. The lowest energy profile of the decarbonylation pathway K.

The effect of $\mathrm{LiCl}$ and $\mathrm{H}_{2} \mathrm{O}$. We had proposed earlier that the rate enhancement effect of $\mathrm{H}_{2} \mathrm{O}$ and $\mathrm{LiCl}$ could be explained by the inhibition of inactive iridium clusters. ${ }^{9}$ However, when $\mathbf{1}$ was reacted with benzyl alcohol in the presence of an excess of $\mathrm{H}_{2} \mathrm{O}$ and $\mathrm{LiCl}$, the clusters at $11.2 \mathrm{ppm}$ and -11.6 ppm were still observed, but the formation of 4 was inhibited which suggests the effect may be due to the basic properties of $\mathrm{H}_{2} \mathrm{O}$ and $\mathrm{LiCl}$. Stronger bases, although, such as $\mathrm{K}_{2} \mathrm{CO}_{3}$ retard the overall trans- formation. ${ }^{9}$ To distinguish between $\mathrm{H}_{2} \mathrm{O}$ and $\mathrm{LiCl}$, two additional experiments were conducted: one with an excess of $\mathrm{H}_{2} \mathrm{O}$ and one with an excess of extensively dried $\mathrm{LiCl}$. The $\mathrm{H}_{2} \mathrm{O}$ experiment showed inhibition of $\mathbf{4}$, while the experiment with $\mathrm{LiCl}$ gave a higher conversion of benzyl alcohol, but only traces of $3 \mathbf{A}$ and $3 \mathbf{B}$ could be observed in the ${ }^{1} \mathrm{H}$ NMR spectrum. A ${ }^{31} \mathrm{P}$ NMR spectrum of the $\mathrm{LiCl}$ experiment revealed complete conversion of $\mathbf{1}$ and the formation of a new complex with two singlet peaks of equal integrals at $44.2 \mathrm{ppm}$ and $25.2 \mathrm{ppm}$. The IR spectrum showed a strong absorbance at $1955 \mathrm{~cm}^{-1}$, proving that the $\mathrm{CO}$ ligand was still coordinated. To obtain more information, the newly observed species was labeled with $\left[{ }^{13} \mathrm{C}\right] \mathrm{CO}$ from $\alpha-\left[{ }^{13} \mathrm{C}\right]$-benzyl alcohol, which afforded a double doublet in the ${ }^{13} \mathrm{C}$ NMR spectrum at $167.4 \mathrm{ppm}$ and changed the two singlets in the ${ }^{31} \mathrm{P}$ NMR spectrum into two doublets with couplings of 3.5 and $14.3 \mathrm{~Hz}$, respectively. The disappearance of the C-P trans-coupling and the P-P cis-coupling from 1, indicates that one of the phosphines has dissociated. Unfortunately, we were not successful in obtaining a crystal structure. The complex does possess catalytic activity, although with a lower conversion rate than 1 . Starting from $[\operatorname{Ir}(\operatorname{cod}) \mathrm{Cl}]_{2}$ and racBINAP, a crude ${ }^{31} \mathrm{P}$ NMR spectrum was recorded after 15 turnovers in the decarbonylation of 3,4,5trimethoxybenzaldehyde at $164{ }^{\circ} \mathrm{C}$ in mesitylene $/ \mathrm{H}_{2} \mathrm{O}(150$ $\mathrm{ppm}$ ) which verified that $\mathbf{1}$ is still the major iridium species present. These observations show that phosphine dissociation is indeed possible under the reaction conditions as required in pathway $\mathrm{K}$ and if the phosphine dissociation is rate determining it also explains the lack of electronic and kinetic isotope effects observed for the decarbonylation.

In 2008 Tsuji et al. reported the decarbonylation of aldehydes with $2.5 \%$ of $[\operatorname{Ir}(\operatorname{cod}) C l]_{2}$ and $5 \%$ of $\mathrm{PPh}_{3}$ in refluxing dioxane, i.e. with an iridium:phosphine ratio of 1:1. ${ }^{6 c}$ Lower yields were observed when the same reaction was performed with an iridium:phosphine ratio of 1:2 by using either $10 \%$ of $\mathrm{PPh}_{3}$ or $5 \%$ of rac-BINAP. This indicates that the catalytically active species has less than two phosphines coordinated to iridium in the optimum system. Furthermore, a KIE of 1.70 was measured with $2.5 \%$ of $[\operatorname{Ir}(\operatorname{cod}) \mathrm{Cl}]_{2}$ and $5 \%$ of $\mathrm{PPh}_{3}{ }^{6 \mathrm{c}}$ which further illustrates the kinetic differences to the present system with $[\mathrm{Ir}(\operatorname{cod}) \mathrm{Cl}]_{2}$ and rac-BINAP. Most likely, the higher reaction temperature needed in the present system is explained by the higher energy required for phosphine dissociation in pathway $\mathrm{K}$.

The synthesis of iridium carbonyl complexes from $[\operatorname{Ir}(\operatorname{cod}) \mathrm{Cl}]_{2}$ and benzyl alcohol could be extended to a number of other phosphine ligands. In the presence of BIPHEP the complex $\operatorname{IrCl}(\mathrm{CO}) \mathrm{BIPHEP}$ was isolated as an orange solid in $66 \%$ yield. This is in line with our original ligand screening where BIPHEP gave results which were comparable with BINAP. ${ }^{9}$ 1,2(Diphenylphosphino)benzene produced an unstable complex that rapidly went from orange to green, which is 
probably the reason that this ligand only gave a few turnovers in the dehydrogenative decarbonylation. ${ }^{9}$ 1,3(Diphenylphosphino)propane (dppp), which should resemble BINAP with regard to the bite angle, ${ }^{32}$ afforded a yellow dimeric carbonyl complex. ${ }^{33}$ The complex $[\mathrm{IrCl}(\mathrm{CO}) \mathrm{dppp}]_{2}$ coordinated molecular oxygen very easily which can be seen in the crystal structure (supporting information). Vaska's complex could not be formed with benzyl alcohol as the CO source, but with benzaldehyde, $\operatorname{IrCl}(\mathrm{CO})\left(\mathrm{PPh}_{3}\right)_{2}$ was formed cleanly in the presence of $[\operatorname{Ir}(\operatorname{cod}) \mathrm{Cl}]_{2}$ and triphenylphosphine. The decarbonylation was carried out in refluxing mesitylene since the same reaction in toluene only afforded the complex $\mathrm{IrCl}(\mathrm{cod}) \mathrm{PPh}_{3}$. It has previously been observed that Vaska's complex does not dehydrogenate an alcohol without the presence of a strong base. ${ }^{34}$ These results again illustrate that monodentate phosphine ligands are less effective in the dehydrogenation cycle.

\section{Conclusion}

In summary, the overall proposed catalytic cycles are composed of pathway $\mathrm{D}$ for the dehydrogenation and pathway $\mathrm{K}$ for the decarbonylation as illustrated in Figure 13. The formation of 1 occurs within seconds after initiation of the reaction. Experimental observations and DFT calculations suggest substitution of chloride with the alcohol to form $\mathrm{HCl}$, which can be temporarily stored by reversible oxidative addition to $\mathbf{1}$. Complex $\mathbf{6}$ is able to undergo $\beta$-hydride elimination according to DFT calculations and the resulting aldehyde dissociates from complex 7 followed by oxidative addition of $\mathrm{HCl}$. DFT calculations indicate that the involvement of the $\operatorname{IrHCl}_{2}(\mathrm{CO}) \mathrm{BINAP}$ lowers the energetic span of the dehydrogenation cycle. The reductive elimination of molecular hydrogen from complex 3 occurs readily under the reaction conditions, as was concluded after heating the dihydride complex in mesitylene.

The decarbonylation is initiated by oxidative addition of the aldehyde to complex $\mathbf{1}$. The coordination of carbon monoxide was shown to be reversible which indicates that $\mathrm{CO}$ is liberated from the dicarbonyl complex 5. The phosphine dissociation pathway explains the lack of a KIE and electronic effects in the decarbonylation. The rate enhancement effect of $\mathrm{H}_{2} \mathrm{O}$ was explained by its basic properties and the effect of $\mathrm{LiCl}$ is speculated to aid in the phosphine dissociation. This completes the two catalytic cycles and highlights the multiple roles of a single complex in a tandem catalytic transformation.

\section{ASSOCIATED CONTENT}

\section{Supporting Information}

Experimental procedures as well as spectroscopic, crystallographic and computational data. This material is available free of charge via the Internet at http://pubs.acs.org.

\section{AUTHOR INFORMATION}

\section{Corresponding Author}

phera@organ.su.se rm@kemi.dtu.dk

\section{Notes}

The authors declare no competing financial interest.

\section{ACKNOWLEDGMENT}

We thank The Danish Council for Strategic Research and Nordic Energy Research (N-INNER II) for financial support. Thishana Singh acknowledges the NRF South Africa and the College of Agriculture, Engineering and Science at the University of KwaZulu-Natal, South Africa for a postdoctoral research fellowship.

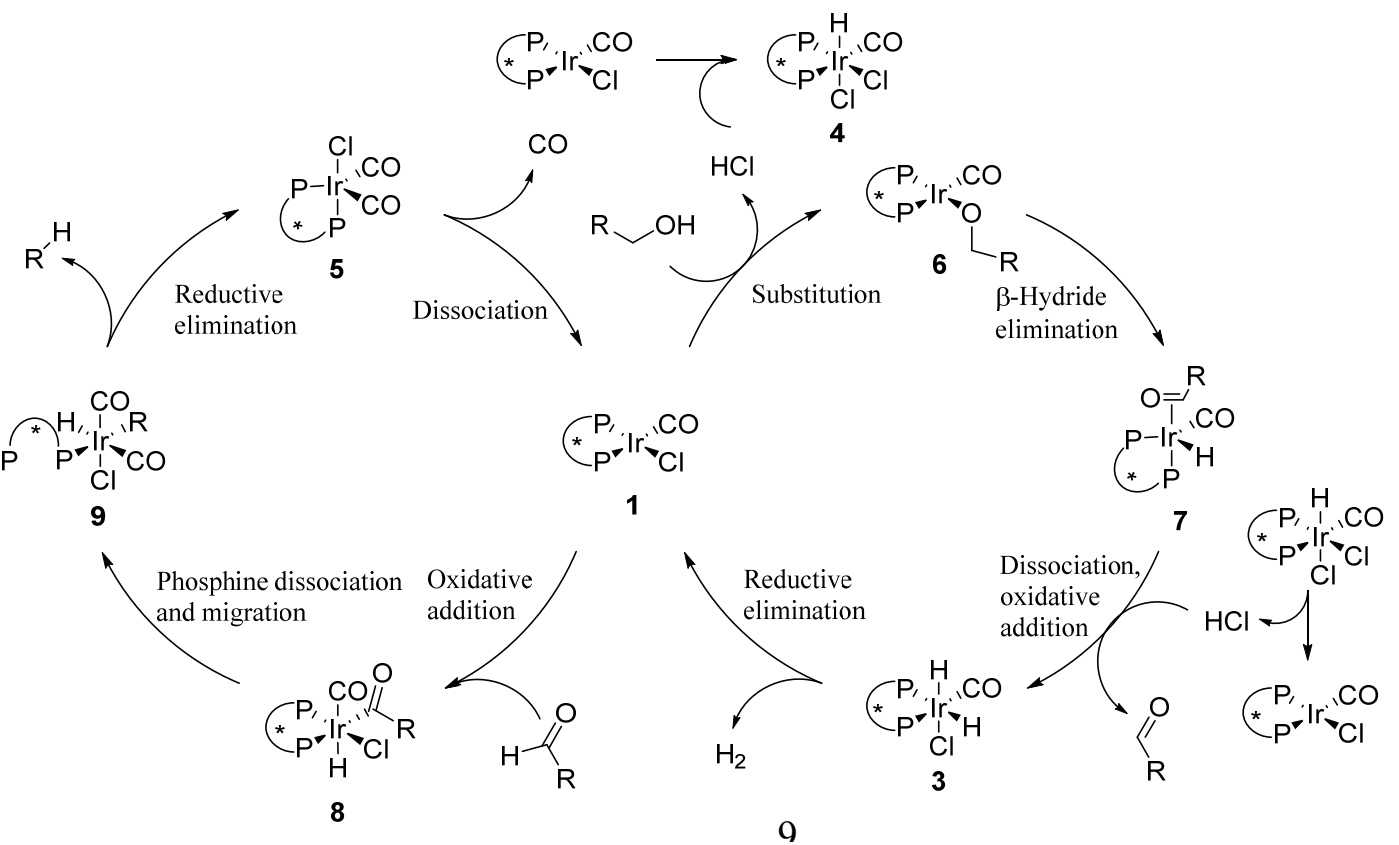

Figure 13. The proposed catalytic cycles. 


\section{REFERENCES}

1 (a) Nielsen, M.; Alberico, E.; Baumann, W.; Drexler, H.-J.; Junge, H.; Gladiali, S.; Beller, M. Nature 2013, 495, 85-89. (b) Rodríguez-Lugo, R. E.; Trincado, T.; Vogt, M.; Tewes, F.; Santiso-Quinones, G.; Grützmacher, H. Nature Chem. 2013, 5, 342-347. (c) Nielsen, M.; Kammer, A.; Cozzula, D.; Junge, H.; Gladiali, S.; Beller, M. Angew. Chem. Int. Ed. 2011, 50, 95939597.

2 (a) Gunanathan, C.; Milstein, D. Science 2013, 341, 1229712. (b) Bähn, S.; Imm, S.; Neubert, L.; Zhang, M.; Neumann, H.; Beller, M. ChemCatChem 2o11, 3, 1853-1864. (c) Obora, Y.; Ishii, Y. Synlett, 2011, 30-51. (d) Dobereiner, G. E.; Crabtree, R. H. Chem. Rev. 2010, 110, 681-703.

3 (a) Ye, X.; Plessow, P. N.; Brinks, M. K.; Schelwies, M.; Schaub, T.; Rominger, F.; Paciello, R.; Limbach, M.; Hofmann, P. J. Am. Chem. Soc. 2014, 136, 5923-5929. (b) Warner, M. C.; Bäckvall, J.-E. Acc. Chem. Res. 2013, 46, 2545-2555. (c) Polukeev, A. V.; Petrovskii, P. V.; Peregudov, A. S.; Ezernitskaya, M. G.; Koridze, A. A. Organometallics 2013, 32, 1000-1015. (d) Makarov, I. S.; Fristrup, P.; Madsen, R. Chem. Eur. J. 2012, 18, 15683-15692. (e) Fristrup, P.; Tursky, M.; Madsen, R. Org. Biomol. Chem. 2012, 10, 2569-2577.

4 (a) Qu, S.; Dang, Y.; Song, C.; Wen, M.; Huang, K.-W.; Wang, Z.-X. J. Am. Chem. Soc. 2014, 136, 4974-4991. (b) Li, H.; Hall, M. B. J. Am. Chem. Soc. 2014, 136, 383-395. (c) Yang, X. ACS Catal. 2014, 4, 1129-1133. (d) Zeng, G.; Sakaki, S.; Fujita, K.; Sano, H.; Yamaguchi, R. ACS Catal. 2014, 4, 1010-1020. (e) Cho, D.; Ko, K. C.; Lee, J. Y. Organometallics, 2013, 32, 45714576. (f) Sandhya, K. S.; Suresh, C. H. Organometallics, 2013, 32, 2926-2933. (g) Sieffert, N.; Bühl, M. J. Am. Chem. Soc. 2010, 132, 8056-8070.

5 (a) Kreis, M.; Palmelund, A.; Bunch, L.; Madsen, R. Adv. Synth. Catal. 2006, 348, 2148-2151. (b) Beck, C. M.; Rathmill, S. E.; Park, Y. J.; Chen, J.; Crabtree, R. H.; Liable-Sands, L. M.; Rheingold, A. L. Organometallics, 1999, 18, 5311-5317. (c) Doughty, D. H; Pignolet, L. H. J. Am. Chem. Soc. 1978, 100, 7083-7085.

6 (a) Adams, J. J.; Arulsamy, N.; Roddick, D. M. Organometallics, 2012, 31, 1439-1447. (b) Geilen, F. M. A.; vom Stein, T.; Engendahl, B.; Winterle, S.; Liauw, M. A.; Klankermayer, J.; Leitner, W. Angew. Chem. Int. Ed. 2011, 50, 6831-6834. (c) Iwai, T.; Fujihara, T.; Tsuji, Y. Chem. Commun. 2008, 62156217.

7 Modak, A.; Deb, A.; Patra, T.; Rana, S.; Maity, S.; Maiti, D. Chem. Commun. 2012, 48, 4253-4255.

8 Fristrup, P.; Kreis, M.; Palmelund, A.; Norrby, P.-O.; Madsen, R. J. Am. Chem. Chem. 2008, 130, 5206-5215.

9 Olsen, E. P. K.; Madsen, R. Chem. Eur. J. 2012, 18, 16023-16029.

10 (a) Shindoh, N.; Takemoto, Y.; Takasu, K. Chem. Eur. J. 2oo9, 15, 12168-12179. (b) Alcaide, B.; Almendros, P.; Luna, A. Chem. Rev. 2009, 109, 3817-3858. (c) Wasilke, J.-C.; Obrey, S. J.; Baker, R. T.; Bazan, G. C. Chem. Rev. 2005, 105, 1001-1020. (d) Fogg, D. E.; dos Santos, E. N. Coord. Chem. Rev. 2004, 248, 2365-2379.

11 (a) Leitch, D. C.; Labinger, J. A.; Bercaw, J. E. Organometallics 2014, 33, 3353-3365. (b) Young, A.; Vincent, M. A.; Hillier, I. H.; Percy, J. M.; Tuttle, T. Dalton Trans. 2014, 43, 8493-8498. (c) Higman, C. S.; Plais, L.; Fogg, D. E. ChemCatChem 2013, 5 , 3548-3551. (d) Pijnenburg, N. J. M.; Cabon, Y. H. M.; van Koten, G.; Klein Gebbink, R. J. M. Chem. Eur. J. 2013, 19, 48584868 .
12 (a) Christensen, S. H.; Olsen, E. P. K.; Rosenbaum, J.; Madsen, R. Org. Biomol. Chem. 2015, 13, 938-945. (b) Verendel, J. J.; Nordlund, M.; Andersson, P. G. ChemSusChem, 2013, 6, 426429 .

13 Ho, H.-A.; Manna, K.; Sadow, A. D. Angew. Chem. Int. Ed. 2012, 51, 8607-8610.

14 Modak, A.; Naveen, T.; Maiti, D. Chem. Commun., 2013, 49, 252-254.

15 Behr, A.; Vorholt, A. J.; Ostrowski, K. A.; Seidensticker, T. Green Chem. 2014, 16, 982-1006.

16 Atesin, A. Ç.; Duckett, S. B.; Flaschenriem, C.; Brennessel, W. W.; Eisenberg, R. Inorg. Chem. 2007, 46, 1196-1204.

17 Rosini, G. P.; Liu, F.; Jespersen, K. K.; Goldman, A. S.; Li, C.; Nolan, S. P. J. Am. Chem. Soc. 1998, 120, 9256-9266.

18 Gómez-Gallego, M.; Sierra, M. A. Chem. Rev. 2o11, 111, 48574963.

19 (a) Kunin, A. J.; Johnson, C. E.; Maguire, J. A.; Jones, W. D.; Eisenberg, R. J. Am. Chem. Soc. 1987, 109, 2963-2968. (b) Kunin, A. J.; Farid, R.; Johnson, C. E.; Eisenberg, R. J. Am. Chem. Soc. 1985, 107, 5315-5317. (c) Johnson, C. E.; Eisenberg, R. J. Am. Chem. Soc. 1985, 107, 3148-316o.

20 Blum, O.; Milstein, D. J. Am. Chem. Soc. 2002, 124, 1145611467.

21 Blum, O.; Milstein, D. J. Organomet. Chem. 200o, 593-594, 479-484.

22 Zhao, J.; Hesslink, H.; Hartwig, J. F. J. Am. Chem. Soc. 2001, 123, 7220-7227.

23 Vaska, L. Acc. Chem. Res., 1968, 1, 335-344.

24 (a) Xu, Y.; Celik, M. A.; Thompson, A. L.; Cai, H.; Yurtsever, M.; Odell, B.; Green, J. C.; Mingos, D. M. P.; Brown, J. M. Angew. Chem. Int. Ed. 2009, 48, 582-585. (b) Dervisi, A.; Carcedo, C.; Ooi, L. Adv. Synth. Catal. 2oo6, 348, 175-183. (c) Smidt, S. P.; Zimmermann, N.; Studer, M.; Pfaltz, A. Chem. Eur. J. 2004, 10, 4685-4693. (d) Smidt, S. P.; Pfaltz, A.; Martínez-Viviente, E.; Pregosin, P. S.; Albinati, A. Organometallics 2003, 22, 1000-1009. (e) Crabtree, R. Acc. Chem. Res. 1979, 12, 331-337

25 Schwartz, J.; Cannon, J. B. J. Am. Chem. Soc. 1974, 96, 22762278.

26 Wertz, D. H. J. Am. Chem. Soc. 1980, 102, 5316-5322.

27 An additional "outer sphere" mechanism for the dehydrogenation was also considered (see ref. $4 \mathrm{~g}$ ). In this pathway, alkoxo complex $\mathrm{d} 2$ reacts with another molecule of benzyl alcohol through a six-membered ring with the simultaneous transfer of the hydride and the proton to iridium and oxygen, respectively. Unfortunately, we were never able to locate a suitable transition state for this pathway.

28 Hermange, P.; Lindhardt, A. T.; Taaning, R. H.; Bjerglund, K.; Lupp, D.; Skrydstrup, T. J. Am. Chem. Soc. 2011, 133, 60616071.

29 Burk, M. J.; Crabtree, R. H. Inorg. Chem. 1986, 25, 931-932.

30 (a) Sieffert, N.; Réocreux, R.; Lorusso, P.; Cole-Hamilton, D. J.; Bühl, M. Chem. Eur. J. 2014, 20, 4141-4155. (b) Shuai, Q.; Yang, L.; Guo, X.; Baslé, O.; Li, C.-J. J. Am. Chem. Soc. 2010, 132, 12212-12213. (c) Garralda, M. A. Dalton Trans. 2009, 36353645. (d) Guo, X.; Wang, J.; Li, C.-J. J. Am. Chem. Soc. 2oo9, 131, 15092-15093.

31 Cordaro, J. G.; Bergman, R. G. J. Am. Chem. Soc. 2004, 126, 16912-16929. 
32 Birkholz, M.-N.; Freixab, Z.; van Leeuwen, P. W. N. M. Chem. Soc. Rev. 2009, 38, 1099-1118.

33 Zotto, A. D.; Costella, L.; Mezzetti, A.; Rigo, P. J. Organomet. Chem. 1991, 414, 109-118.

34 Huang, J.-L.; Dai, X.-J.; Li, C.-J. Eur. J. Org. Chem. 2013, 64966500. 
Table of Contents artwork

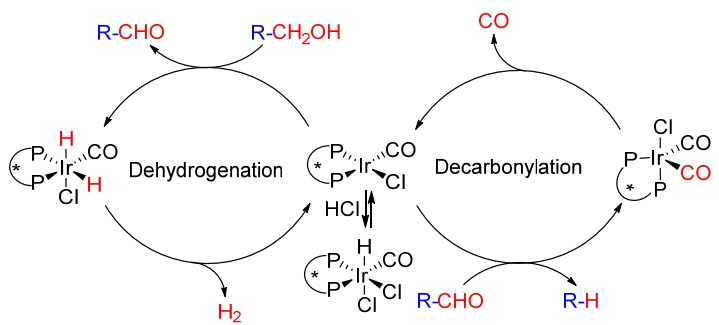

